\title{
Interannual variability of the South Pacific Convergence Zone and implications for tropical cyclone genesis
}

\author{
Emmanuel M. Vincent $\cdot$ Matthieu Lengaigne • \\ Christophe E. Menkes · Nicolas C. Jourdain • \\ Patrick Marchesiello • Gurvan Madec
}

Received: 2 October 2009/ Accepted: 26 November 2009

(C) Springer-Verlag 2009

\begin{abstract}
The interannual variability of the South Pacific Convergence Zone (SPCZ) and its influence on tropical cyclone (TC) genesis in the South Pacific are investigated using observations and ERA40 reanalysis over the 19792002 period. In austral summer, the SPCZ displays four typical structures at interannual timescales. The first three are characterized by a diagonal orientation of the SPCZ and account for $85 \%$ of the summer seasons. One is close to climatology and the other two exhibit a $3^{\circ}$ northward or southward departure from the SPCZ climatological position. In contrast, the fourth one, that only encompasses three austral summer seasons (the extreme 1982/1983 and 1997/1998 El Niño events and the moderate 1991/1992 El
\end{abstract}

E. M. Vincent · M. Lengaigne - C. E. Menkes - G. Madec Laboratoire d'Océanographie et du Climat: Expérimentation et Approches Numériques (LOCEAN), IRD/UPMC/CNRS/ MNHN, Paris, France

M. Lengaigne

National Institute of Oceanography, Goa, India

C. E. Menkes · N. C. Jourdain · P. Marchesiello Institut de Recherche pour le Développement, Nouméa, New Caledonia

P. Marchesiello

Laboratoire d'Etudes en Géophysique et Océanographie Spatiale

(LEGOS), CNES/CNRS/UPS/IRD, Toulouse, France

G. Madec

National Oceanographic Centre, Southampton, UK

E. M. Vincent $(\square)$

LOCEAN/IPSL, UPMC, Boîte 100, 4, place Jussieu,

75252 Paris Cedex 05, France

e-mail: emmanuel.vincent@locean-ipsl.upmc.fr
Niño event), displays very peculiar behaviour where the SPCZ largely departs from its climatological position and is zonally oriented. Variability of the western/central Pacific equatorial sea surface temperature (SST) is shown to modulate moisture transport south of the equator, thereby strongly constraining the location of the SPCZ. The SPCZ location is also shown to strongly modulate the atmospheric circulation variability in the South Pacific with specific patterns for each class. However, independently of its wide year-to-year excursions, the SPCZ is always collocated with the zero relative vorticity at low levels while the maximum vorticity axis lies $6^{\circ}$ to the south of the SPCZ position. This coherent atmospheric organisation in the SPCZ region is shown to constrain tropical cyclogenesis to occur preferentially within $10^{\circ}$ south of the SPCZ location as this region combines all the large-scale atmospheric conditions that favour the breeding of TCs. This analysis also reveals that cyclogenesis in the central Pacific (in the vicinity of French Polynesia) only occurs when the SPCZ displays a zonal orientation while this observation was previously attributed to El Niño years in general. Different characteristics of El Niño Southern Oscillation (ENSO)related Pacific equatorial warming are shown to impact differently on the SPCZ position, suggesting that for regional scales, such as the South Pacific, the SPCZ classification is more appropriate than a simple ENSO index to characterize TC interannual variability. These findings suggest that forecasting the strength of El Niño through SST variations in the eastern Pacific may not be sufficient to accurately predict cyclogenesis in the South Pacific, especially east of the dateline.

Keywords South Pacific Convergence Zone . Interannual variability - Tropical cyclone .

El Niño Southern Oscillation 


\section{Introduction}

The South Pacific Convergence Zone (SPCZ) is characterized by a band of high cloudiness, strong convective precipitation and low-level convergence extending from the west Pacific warm pool south-eastward towards French Polynesia (Fig. 1; see review by Vincent 1994). It is the only intertropical convergence zone (ITCZ) of the southern hemisphere present all year round, although it is best developed during austral summer. It has been suggested that the summertime SPCZ consists of a zonal portion located over the western Pacific warm-pool region and a diagonal portion oriented along a northwest-southeast axis east of $170^{\circ} \mathrm{E}$ (Vincent 1994). The climatological characteristics of its eastern portion have been thought to rely on the interactions with higher latitude depressions (Kiladis et al. 1989) and on the existence of a dry zone in the southeastern Pacific, controlled by the presence of the Andes (Takahashi and Battisti 2007). On higher frequency timescales (daily to weekly) the zonal dry air inflow associated with trade wind strength has been shown to control the position of the SPCZ eastern margin (Lintner and Neelin 2008). On the other hand, the climatological characteristics and position of its western portion is likely to be influenced by both the underlying sea surface temperature (SST) gradients and the land-ocean distribution (Kiladis et al. 1989). The western part of the SPCZ is strongly influenced by the vast monsoon system that affects the Indian Ocean and Australian region, with monsoon winds extending eastward until the dateline in the SPCZ region (Fig. 1).

The SPCZ plays a significant role in global climate and is one of the major features of the southern hemisphere climate (Kiladis et al. 1989; Vincent 1994). Because the gradients of precipitation in the vicinity of the SPCZ are very strong, small displacements in its mean position can imply drastic changes in precipitation regimes for islands in the region (Gouriou and Delcroix 2002). Its location not only strongly constrains the hydrological cycle but is also the breeding ground of tropical cyclones (TCs) in the South Pacific. Despite the SPCZ's significance to tropical climate, its characteristics, dynamics and variability have attracted relatively little attention. The interannual variability of the SPCZ location and TC activity in the Australian/western Pacific have been investigated mainly with respect to their relationship with El Niño Southern Oscillation (ENSO). It has been shown that El Niño (La Niña) events tend to occur accordingly with a north-eastward (south-westward) displacement of the SPCZ (Trenberth 1976; Folland et al. 2002) and of a similar displacement of the TC genesis region in the south-western Pacific (Revell and Goulter 1986; Hastings 1990; Basher and Zheng 1995; Kuleshov et al. 2008), while decreasing (increasing) TC activity near Australia (Nicholls 1985; Holland et al. 1988; Evans and Allan 1992; Ramsay et al. 2008). Although the SPCZ and the region of TC activity in the southwest Pacific are displaced in a similar fashion during ENSO events, the detailed mechanisms and the extent to which SPCZ controls the large scale environment favouring cyclonic activity have not yet been investigated. In addition, the characteristics of El Niño events vary widely from one event to another, and the influence of this diversity on the SPCZ location and TC activity has been overlooked in the aforementioned studies. Differentiating extreme cases (1982/1983 and 1997/1998 events) from other El Nino events has been shown to be critical since the two types of event display contrasted predictability, spatial patterns and mechanisms (Vecchi 2006; Lengaigne and Vecchi 2009). In addition, the location of the maximum equatorial warming has been also shown to strongly modulate the atmospheric teleconnections (Ashok et al. 2007; Trenberth and Smith 2006) and to have different impacts on cyclonic activity in the Atlantic basin (Kim et al. 2009). Evidently, El Niño strength classification is subjective and is usually based on simple indices such as the southern oscillation

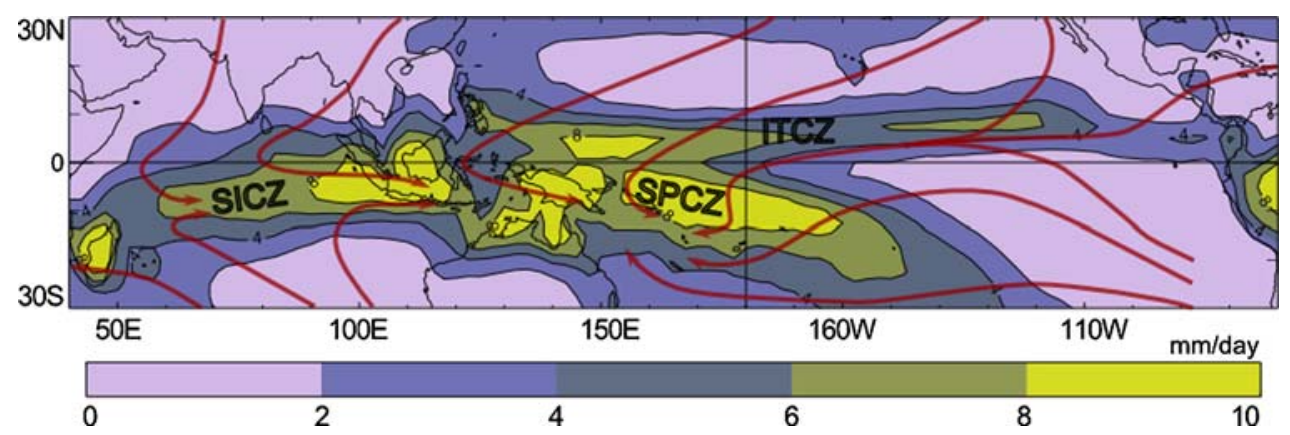

Fig. 1 Indo-Pacific climatology of December-January-February (DJF) precipitation (GPCP). Convergence zone positions are shown: InterTropical Convergence Zone (ITCZ), South Pacific Convergence Zone (SPCZ), South Indian Convergence Zone (SICZ). Dark red arrows are a few streamlines extracted from the ERA40 DJF-mean surface winds in the region; we outline the vast monsoon system affecting the Indian Ocean, Australia and western part of the SPCZ 
index (SOI) or eastern equatorial Pacific SST anomalies, and a large number of thresholds have been used to account for the definition and strength of El Niño while the spatial patterns of warming are rarely taken into account (Ashok et al. 2007). Alternatively, El Niño strength can be defined by the characteristics of its regional impacts. Redefining regional indices accounting for the local effect of ENSO is shown to be appropriate for regional studies as illustrated by Wang and Hendon (2007). Our study investigates the influence of ENSO on TC activity in the South Pacific through its regional influence on the SPCZ. It will allow a better understanding and description of interannual cyclogenesis variability in the region.

The objectives of this study are therefore (1) to provide a detailed description of the interannual variability of the SPCZ (without presupposing a link with ENSO), (2) to understand the extent to which the SPCZ location modulates cyclogenesis activity and (3) to differentiate changes in TC activity in the South Pacific region depending on El Niño characteristics. The paper is structured as follows: Sect. 2 describes the data and methods used to describe the SPCZ. Section 3 focuses on the description of SPCZ interannual variability, i.e., the variability of its position and dynamical structure and the forcings driving this variability. The implications of the SPCZ displacement and related dynamical variables on the genesis of TCs are investigated in Sect. 4. A summary and discussion are given in the last section.

\section{Characterization of the SPCZ: data and methods}

Although the SPCZ can be seen throughout the year, it is only fully developed from November to April. In December, January and February (DJF), the SPCZ reaches its maximum extension and the climatological precipitation field shows little month-to-month variability in magnitude and geographical pattern. DJF composites of precipitation fields are therefore used to characterise the austral summer SPCZ of year $n / n+1$ and to examine its interannual variability.

\subsection{Localization of the SPCZ}

To define the position of the SPCZ, we seek to select observations that are homogeneous (satellite acquired) and span a period long enough to encompass the largest number of El Niño/La Niña events. In previous studies, the SPCZ has been defined by the maximum of cloud cover or minimum in outgoing longwave radiation (OLR) using satellitebased observations, or by surface wind convergence using global atmospheric reanalysis. Observed surface convergence can be obtained using the European Remote Sensing Satellite (ERS-1) scatterometer and the NASA Quick
Scatterometer (QuickSCAT) but this combined satellite wind field is only available from 1993 onwards, which is too short a period for the purpose of this study. Cloudiness or precipitation products are available at least from 1984 onwards and can be used to locate the SPCZ. Cloud cover is available from the International Satellite Cloud Climatology Project data set (ISCCP) or through OLR data (a proxy for deep convection) from NOAA. Precipitation is available in the data set from the Global Precipitation Climatology Project version 2 (GPCP; Adler et al. 2003) or the Climate Prediction Center Merged Analysis of Precipitation (CMAP; Xie and Arkin 1997).

Estimations of the climatological location of the SPCZ using the various cloud and precipitation data set give very similar results between $160^{\circ} \mathrm{E}$ and $160^{\circ} \mathrm{W}$ (Fig. 2a), but display differences east of $155^{\circ} \mathrm{W}$ between cloud cover and precipitation based estimations. The discrepancies may be due to the larger sensitivity of total cloud cover and OLR to low level clouds in the extra-tropical south-eastern end of the SPCZ. We carry out further analysis using the precipitation maximum definition in the rest of this study because the two available datasets (GPCP and CMAP) allow us to assess the degree of confidence in the data describing the SPCZ. GPCP will be used as our reference dataset as it has been shown to give more realistic tropical precipitation magnitudes over the ocean (Yin et al. 2004). However, the main results of this study remain valid when cloud cover and OLR data are used to define the SPCZ position.

For each DJF season, the mean SPCZ position at each longitude is taken as the position of the maximum precipitation between the equator and $30^{\circ} \mathrm{S}$. The line obtained by joining the latitude of the SPCZ at each longitude is referred to as the SPCZ position. The SPCZ region is
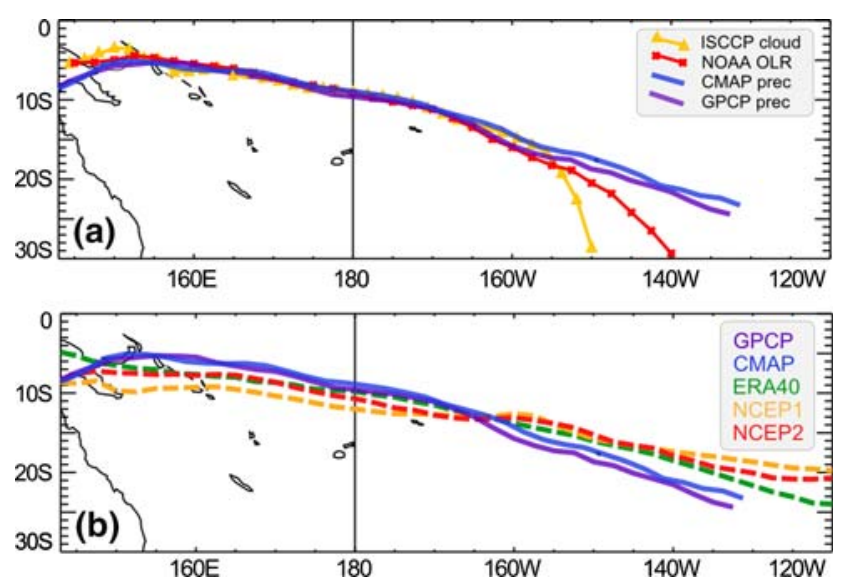

Fig. 2 a Mean position of the SPCZ as determined by different proxies for the period 1979-2002 (except for ISCCP on 1984-2002 period). b Comparison of SPCZ position in reanalyses and observations. In this figure, the SPCZ location is defined as the position of the maximum of the corresponding field (minimum for the OLR field) between the equator and $30^{\circ} \mathrm{S}$ 
Table 1 SPCZ mean latitude in its central region and mean slope (as determined from a linear fit to the SPCZ position). Standard deviation of the latitude of the SPCZ in its central region. Correlations of the averaged latitude and slope of the SPCZ of each reanalysis to GPCP on the 1979-2002 DJF seasons

\begin{tabular}{lcccc}
\hline & GPCP & CMAP & ERA40 & NCEP1 \\
\hline SPCZ mean latitude in $160^{\circ} \mathrm{E}-140^{\circ} \mathrm{W}\left({ }^{\circ} \mathrm{S}\right)$ & 12.2 & 11.9 & 11.3 & 12.5 \\
$\mathrm{SPCZ}$ mean slope $\left({ }^{\circ} \mathrm{S} /{ }^{\circ} \mathrm{E}\right)$ & 0.27 & 0.26 & 0.2 & 0.14 \\
$\mathrm{SPCZ}$ standard deviation (in $\left.160^{\circ} \mathrm{E}-140^{\circ} \mathrm{W}\right)$ & 3.2 & 3.1 & 2.3 & 0.17 \\
Correlation with $\mathrm{GPCP}$ of & & & 2.4 \\
Lat of the $\mathrm{SPCZ}\left(160^{\circ} \mathrm{E}-140^{\circ} \mathrm{W}\right)$ & 1 & 0.98 & 0.89 & 0.83 \\
Slope of the $\mathrm{SPCZ}$ & 1 & 0.81 & 0.75 & 0.17 \\
\hline
\end{tabular}

defined as the area where DJF mean precipitation is higher than $6 \mathrm{~mm} /$ day. Points where precipitation is lower than this threshold are not included in the SPCZ line.

\subsection{Choice of the reanalysis}

We rely on atmospheric reanalysis products to describe the dynamical structure of the SPCZ as they are available over extended periods (from at least 1979) and provide a dynamically consistent view of the large-scale convergence zone and its variability.

The climatological characteristics of the SPCZ location given by the precipitation fields of the two reanalyses NCEP1 and NCEP2 from NCEP/NCAR (National Center for Environmental Prediction/National Center for Atmospheric Research) and by the reanalysis ERA40 from ECMWF (European Center for Medium-range Weather Forecasts) are displayed in Fig. $2 \mathrm{~b}$ and summarized in Table 1. The mean latitude of the SPCZ in its central region is found to be close to the observed one for all reanalyses. All reanalysis products, however, underestimate the SPCZ slope determined from satellite data (Table 1). This "zonal bias" is less pronounced in ERA40 compared to NCEP1 and NCEP2, and NCEP1 and NCEP2 display a spurious "double-ITCZ" pattern in the eastern Pacific, especially in 1983/1984, 1984/1985, 1987/1988, 1998/1999 (not shown).

The interannual meridional displacement of the SPCZ in these datasets is compared to GPCP by correlating its zonal mean latitude between $160^{\circ} \mathrm{E}$ and $140^{\circ} \mathrm{W}$ (Table 1). CMAP and GPCP display very coherent temporal variability in phase and amplitude. In comparison, all reanalysis products underestimate the amplitude of the SPCZ position interannual variability by about $30 \%$ (Table 1 ). However, the variability of the SPCZ position and slope is better reproduced in ERA40 than in NCEP reanalyses (Table 1). Based on these findings, ERA40 is chosen in the following to illustrate the dynamical organisation of the SPCZ (part 3.3). The period used for the whole study will span the years 1979-2002 as it is the common period of precipitation observations and ERA40 availability.

\section{Interannual variability of the SPCZ}

3.1 Precipitation variability in the Southwest Pacific

The main modes of interannual variability affecting the SPCZ are extracted by applying a rotated Empirical Orthogonal Function analysis (using the varimax method described in Reyment and Jörekog 1993) to the austral summer precipitation in the South Pacific region $\left(155^{\circ} \mathrm{E}-\right.$ $\left.80^{\circ} \mathrm{W} / 0-30^{\circ} \mathrm{S}\right) .^{1}$ Results are shown for GPCP in Fig. 3. Very similar modes are obtained using CMAP or ERA40 as illustrated by the high correlation of their first two principal components (PCs) to GPCP (Table 2). The first and second EOFs represent, respectively, 52 and $17 \%$ of the total variance in observations (with all other modes lower than $7 \%$ ). Both EOF1 and EOF2 display opposite variability on each side of the mean SPCZ position with largest amplitude, respectively, in the western and eastern parts of the SPCZ (Fig. 3a, b). As seen in Fig. 3c, most years only project onto the first EOF, implying that the precipitation variability is mostly characterised by a north-south movement of the $\mathrm{SPCZ}$ in the $160^{\circ} \mathrm{W}-160^{\circ} \mathrm{E}$ region. Three years only (1982/1983, 1991/1992 and 1997/1998) have positive contributions to both PC1 and PC2. The resulting precipitation pattern is characterized by strong positive precipitation anomalies extending throughout the equatorial Pacific. This EOF analysis therefore reveals that the interannual variability of the SPCZ position differs in its western and eastern portions (described, respectively, by EOF1 and EOF2). To specify the longitude of the transition between these western and eastern behaviours, an EOF analysis on the latitude of the SPCZ at each longitude is performed. It displays a first mode characterising the north-south displacement of the SPCZ and a second mode opposing the variability of the SPCZ location east and west of $175^{\circ} \mathrm{W}$ (not shown). Describing the SPCZ movement using a single index will hence mainly capture the vari-

\footnotetext{
1 The same analysis performed with the eastern boundary at $120^{\circ} \mathrm{W}$ and $140^{\circ} \mathrm{W}$ yields very similar results.
} 
Fig. 3 a, b First and second EOFs of GPCP DJF precipitation on the period 1979-2002, the thick purple line indicates the mean position of the SPCZ, and c coordinates of each year on these two-first modes (colors show the class to which each season belongs, see Fig. 4); year $n$ stands for the DJF season Dec. year $n$ to Feb. year $n+1$
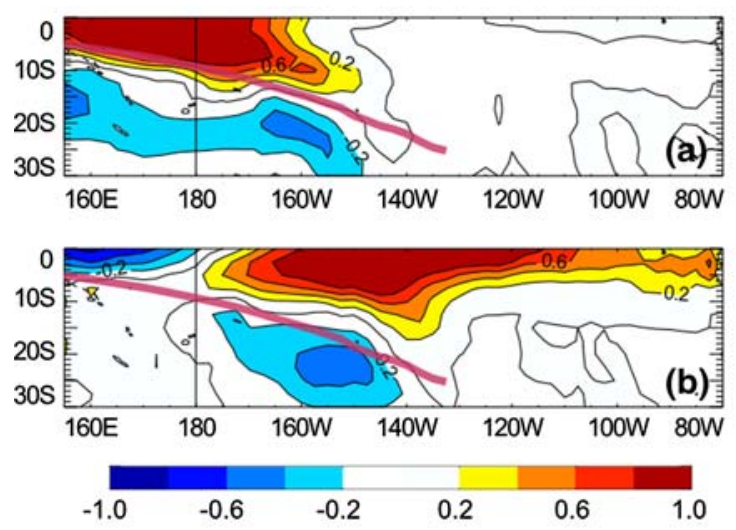

Table 2 Percent variance of the two-first EOFs for ERA40 reanalysis and observations, correlation of the two-first PCs coordinates with respect to GPCP ones

\begin{tabular}{lccc}
\hline & GPCP & CMAP & ERA40 \\
\hline EOF1 (\% variance) & 52 & 53.6 & 53.5 \\
EOF2 (\% variance) & 17.2 & 15 & 15.6 \\
PC1 correlation & 1 & 0.97 & 0.97 \\
PC2 correlation & 1 & 0.96 & 0.92 \\
\hline
\end{tabular}

All correlations significant at the $95 \%$ level with respect to a twotailed Student's $t$ test

ability related to the first EOF. To account for the information contained in both first and second EOFs, we define two indices describing eastern and western regions: latW is the SPCZ latitude averaged between $160^{\circ} \mathrm{E}$ and $180^{\circ}$ and latE is the SPCZ latitude averaged between $170^{\circ} \mathrm{W}$ and $\left.150^{\circ} \mathrm{W}\right)$.

A classification using an ascendant hierarchical clustering (AHC; Ward 1963) method applied to these two variables (latW and latE) is then used to summarize the interannual variability of the SPCZ position. The AHC computes a hierarchical clustering of SPCZ characteristics for the 23 austral summer seasons considered in the analysis. At the first step, there are 23 clusters; then, at each step, the two closest clusters are aggregated according to the Ward criterion with Euclidean distances as the dissimilarity measure. This method ensures a classification in which the elements of a given cluster are as close as possible to each other and as far as possible to elements of other clusters. The resulting dendrogram (or classification tree) shown on Fig. 4a depicts the partitioning from 23 clusters at the bottom of the tree to a unique cluster at the top of it. Each leaf of the tree is a subset of the 23 seasons; each node represents the conjunction of two clusters, the height of its branch being representative of the distance between two clusters. The last important jump of inter- cluster distance as the number of classes increases is seen for a division into four clusters (Fig. 4b). Seasons associated to each of these four classes are highlighted by different colours in Figs. 3c and 4a. Clusters determined by this method do also show up in the PC1-PC2 plane (Fig. 3c) thereby giving confidence that our classification is robust. This observation also confirms that the SPCZ location (on which the classification is performed) accurately summarizes the large-scale precipitation variability in the tropical South Pacific (on which the EOFs are constructed). The same AHC applied to PC1-PC2 coordinates instead of latW-latE indices gives indeed similar clusters. In the following, we will refer to the classification based on latW-latE indices that are, by construction, more representative of the SPCZ location than the EOF analysis (as the EOF analysis also accounts for variations in precipitation intensity within the SPCZ and at the equator). This classification is stable when using CMAP or ERA40 datasets, as well as when the boundaries of the western and eastern boxes are slightly changed.

The SPCZ location for each of the 4 classes is displayed on Fig. 5a. The "negative", "neutral" and "positive" classes are similar to the composites described in Folland et al. (2002). Within these classes, the SPCZ location is shifted in latitude with little change in its slope. In contrast, the "asymmetric" class has never been investigated in detail and is characterized by the SPCZ becoming almost zonal from $150^{\circ} \mathrm{E}$ to $140^{\circ} \mathrm{W}$ and merging with the ITCZ that is no longer observed in the North Pacific, west of $160^{\circ} \mathrm{W}$ (not shown). The corresponding cluster contains only three seasons $(1982 / 1983,1991 / 1992,1997 / 1998)$ and its specificity will be discussed in detail in the following section.

Changes in the position of the SPCZ are also associated with modifications of total precipitation fluxes in the SPCZ region. As seen on Fig. 5b, there is a clear increase of the total precipitation flux from "neutral" to "positive" and "asymmetric" years with $50 \%$ more precipitation during 
Fig. 4 a Dendrogram resulting from the ascendant hierarchical classification $(A H C)$ performed on the two variables: latW and latE. b Inter-cluster distance (in the centred and normalized space of coordinates on the two variables) as a function of the number of classes. Red dashed line indicates the cutting level; four clusters are identified
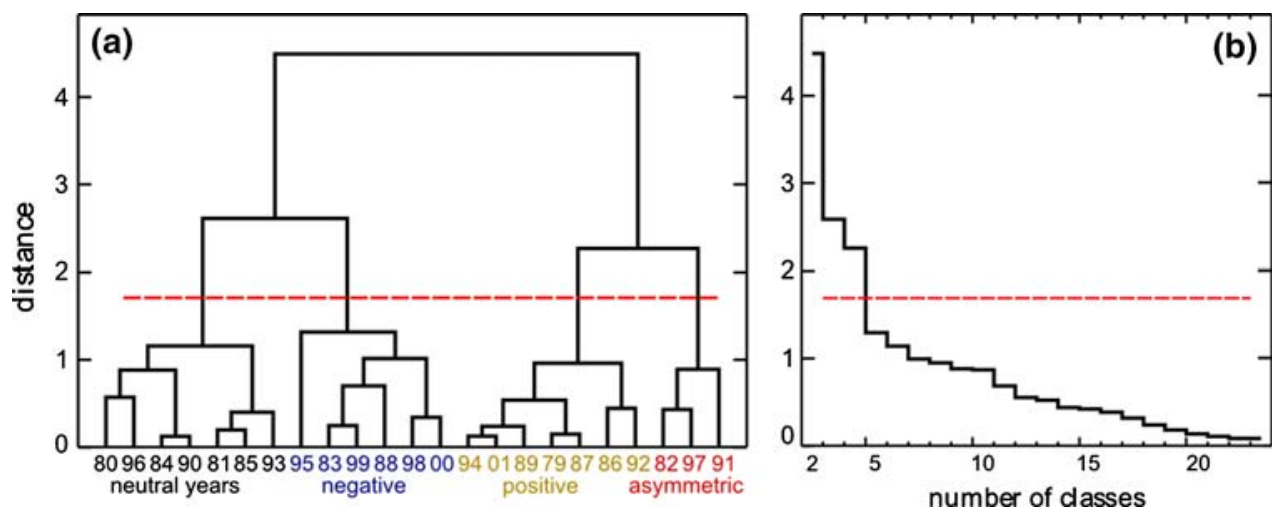

Fig. 5 a Positions of the SPCZ from GPCP for each class. Red "asymmetric", orange "positive", black "neutral" and blue "negative" years. b Total precipitation flux (in Sverdrup) in the SPCZ region $\left(143^{\circ} \mathrm{E}-\right.$ $\left.120^{\circ} \mathrm{W} / 0-30^{\circ} \mathrm{S}\right)$

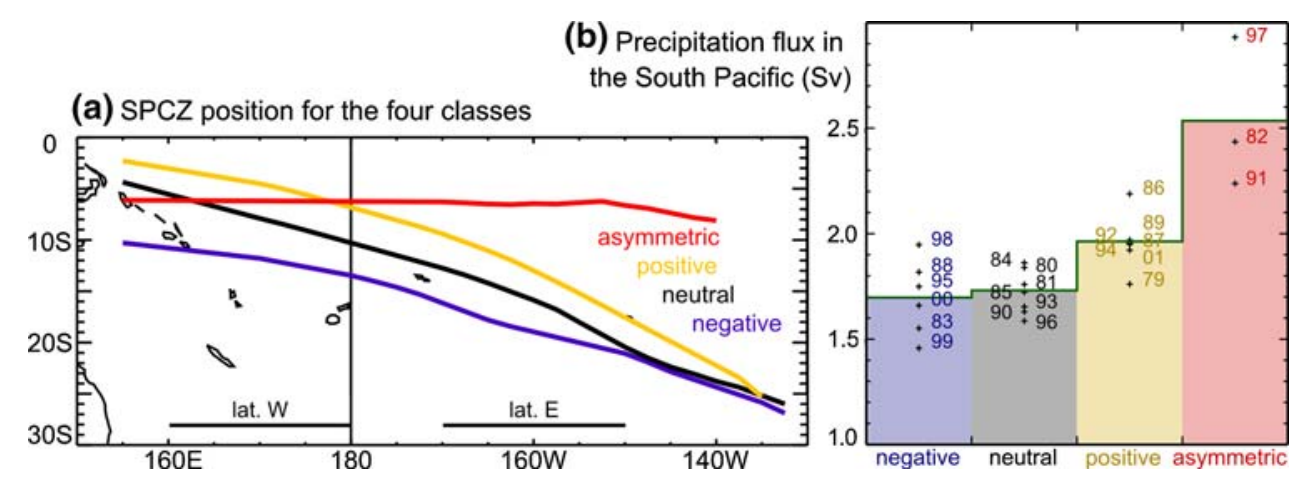

the latter with respect to "neutral" conditions, while "negative" years show little difference from the "neutral" case. The increase of total precipitation is mainly due to the greater extension of the precipitating area (the SPCZ region) rather than an intensification of it. Indeed the area receiving a flux $>6 \mathrm{~mm} /$ day shows a similar $50 \%$ increase between "asymmetric" and "neutral" years while the precipitation rate within the SPCZ varies by $<10 \%$ between classes.

\subsection{SST forcing of SPCZ interannual variability}

In the previous section, a description of the SPCZ interannual variability has been conducted outside of any consideration of ENSO. In this section, we investigate the relation to ENSO and associated SST forcing of SPCZ displacements.

The high value of the correlation coefficients between the SPCZ latitude and the Niño 3 or Niño 3.4 index (Table 3) confirms that SPCZ interannual variability is primarily related to ENSO. However, the SPCZ position in latW is not as well correlated with the classical Niño indices (Niño 3 and Niño 3.4) as in latE (Table 3), mainly because the three "asymmetric" events strongly degrade the correlation. Indeed, in contrast to the "neutral" to "positive" tendency, the SPCZ in latW moves toward the south for these years and is found around $6^{\circ} \mathrm{S}$ (Figs. 5a, 6a) contributing to the zonal orientation of the SPCZ. When
Table 3 DJF correlation coefficients between Niño 3, Niño 3.4 and Niño 4 indexes (HadiSST) and SPCZ position proxies: latW and latE (GPCP); the fourth and fifth rows present the correlations of SPCZ latitude with SST indices that were found to yield the highest correlations (in bold in the table, see text) with the SPCZ indices in latW and latE, respectively

\begin{tabular}{lll}
\hline corr coef & latW & latE \\
\hline Niño 3 & 0.56 & 0.81 \\
Niño 3.4 & 0.71 & 0.83 \\
Niño 4 & 0.84 & 0.70 \\
SST in $170^{\circ} \mathrm{E}-170^{\circ} \mathrm{W} / 5^{\circ} \mathrm{N}-5^{\circ} \mathrm{S}$ & $\mathbf{0 . 8 7}$ & 0.60 \\
Warm Pool eastern margin & 0.64 & $\mathbf{0 . 9 2}$ \\
\hline
\end{tabular}

All correlations significant at the $95 \%$ level with respect to a twotailed Student's $t$ test

discarding these three years from the calculation, the correlation between latW and Niño 3 (Niño 3.4) SST increases to 0.74 (0.81). In agreement with Folland et al. (2002), El Niño (La Niña) years are generally found to drive a northward (southward) displacement of the SPCZ (Table 4). However, SPCZ displacements during El Niño events are more diverse than previously thought: El Niño years separate into two distinct clusters, displaying either a northward shift or a zonal alignment of the SPCZ position. In addition, this relationship is not systematic: three neutral ENSO years display a northward excursion of the SPCZ (1992/1993, 1989/1990 and 2001/2002), which is usually 
Fig. 6 Scatter plot of DJF latitude of the SPCZ a in latW versus SST anomalies in the $170^{\circ} \mathrm{E}-170^{\circ} \mathrm{W} / 5^{\circ} \mathrm{N}-5^{\circ} \mathrm{S}$ region and $\mathbf{b}$ in latE versus easternmost extension of the Warm Pool at the equator (as marked by the $29^{\circ} \mathrm{C}$ SST isotherm in HadiSST dataset). These two SST indices are chosen as they are the ones that yield the highest correlations with latW and latE indexes
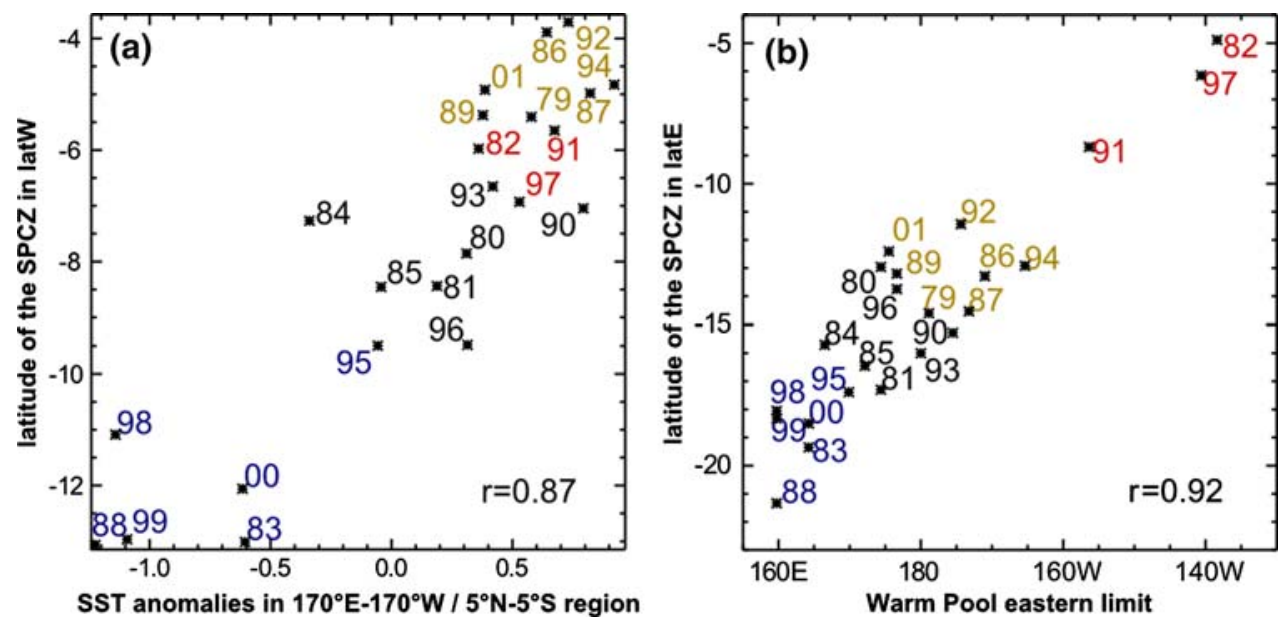

Table 4 Comparison of years belonging to the classes formed by the classification on SPCZ position (left) and on the Niño 3.4 index (right)

\begin{tabular}{ll}
\hline SPCZ position classification & ENSO classification \\
\hline "Asymmetric" years & Niño years \\
1982/1983, 1991/1992, 1997/1998 & $1982 / 1983,1997 / 1998,1991 / 1992,1986 / 1987,1994 / 1995$, \\
& $1987 / 1988,1979 / 1980$ \\
"Positive" years & Neutral ENSO years \\
1992/1993, 1986/1987, 1994/1995, 2001/2002, 1987/1988, & $1992 / 1993,1990 / 1991,1989 / 1990,1993 / 1994,1981 / 1982$, \\
1989/1990, 1979/1980 & $2001 / 2002,1980 / 1981,1996 / 1997,1985 / 1986$ \\
"Neutral" years & Niña years \\
1980/1981, 1984/1985, 1990/1991, 1996/1997, 1985/1986, & $1995 / 1996,1983 / 1984,2000 / 2001,1984 / 1985,1998 / 1999$, \\
1981/1982, 1993/1994 & $1999 / 2000,1988 / 1989$ \\
"Negative" years & \\
$1995 / 1996,1998 / 1999,2000 / 2001,1999 / 2000,1983 / 1984,1988 / 1989$ & \\
\hline$Y$ Years are &
\end{tabular}

Years are ordered by the amplitude of the mean SPCZ displacement (left) and by the amplitude of Niño 3.4 SST anomaly (right)

The monthly temperature averaged over the Niño 3.4 region $5^{\circ} \mathrm{S}-5^{\circ} \mathrm{N}, 170^{\circ} \mathrm{W}-120^{\circ} \mathrm{W}$ is used to characterize the El Niño-La Niña phenomenon. El Niño (La Niña) years are defined as those when the DJF Niño 3.4 SST anomaly is greater than (lower than) $1 / 2^{\circ} \mathrm{C}$ as defined by NOAA in http://www.cpc.noaa.gov/products/analysis_monitoring/ensostuff/ensoyears.shtml

typical of El Niño years, while one La Niña event (1984/ 1985) corresponds to a "neutral" SPCZ season, with a SPCZ close to the climatological position (Table 4).

LatW and latE are both strongly correlated to the equatorial SST variability but the location of SST with which the strongest correlations are found differs between the two indices. While for latW the strongest correlations are found around the dateline $\left(170^{\circ} \mathrm{E}-170^{\circ} \mathrm{W} / 5^{\circ} \mathrm{N}-5^{\circ} \mathrm{S}\right.$; Table 3; Fig. 6a), latE displays the strongest positive correlations with SSTs in the central Pacific $\left(170^{\circ} \mathrm{W}-120^{\circ} \mathrm{W} /\right.$ $5^{\circ} \mathrm{N}-5^{\circ} \mathrm{S}$, i.e., Niño 3.4 region; see Table 3 ). This latter region experiences large fluctuations of the eastern edge of the warm pool during the ENSO cycle. The eastern edge of the warm pool at the equator (here defined by the longitude of the $29^{\circ} \mathrm{C}$ isotherm) arises as a better predictor of eastern SPCZ latitude (latE) than Niño 3 or Niño 3.4 indices (Table 3; Fig. 6b).
In Fig. 7c, we note that the SPCZ is located over a tongue of warm water extending from the warm pool south-eastward into the South Pacific. Associated with SPCZ variability, the SST pattern is deeply modified (Fig. 7a, b, d). SST anomalies have two major impacts of interest in the definition of the SPCZ: they drive surface wind anomalies, and they modulate the amount of humidity available in the lower layers of the troposphere. Because tropical convective regions are primarily forced by moisture convergence, analysing the changes in wind patterns and moisture convergence in relation to the SPCZ variability allow us to better understand the mechanism of SST forcings driving the variations of SPCZ location. For the "positive" cluster, the slight eastward shift of the warm pool eastern boundary results in maximum SST anomalies around $160^{\circ} \mathrm{W}$ driving low level wind anomalies in the western Pacific west of $160^{\circ} \mathrm{W}$ that are maximum just 
Fig. 7 Sea surface temperature (SST) for $\mathbf{c}$ the "neutral" class and $\mathbf{a}, \mathbf{b}, \mathbf{d}$ SST anomalies with respect to the "neutral" class of the "asymmetric", "positive", and "negative" classes, respectively. Black arrows are winds on the $850 \mathrm{hPa}$ level in (b) and anomalies from the "neutral" winds on other panels
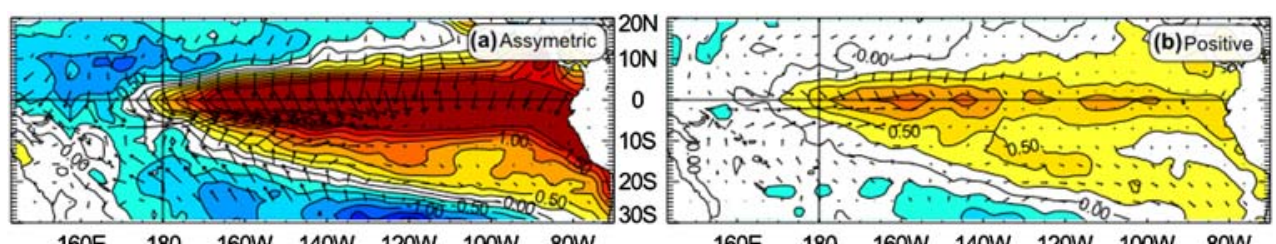

160E 180 160W 140W 120W 100W 80W

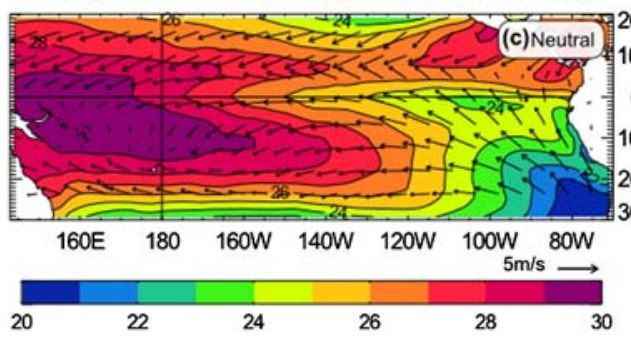

$160 \mathrm{E} 180$ 160W 140W 120W 100W 80W
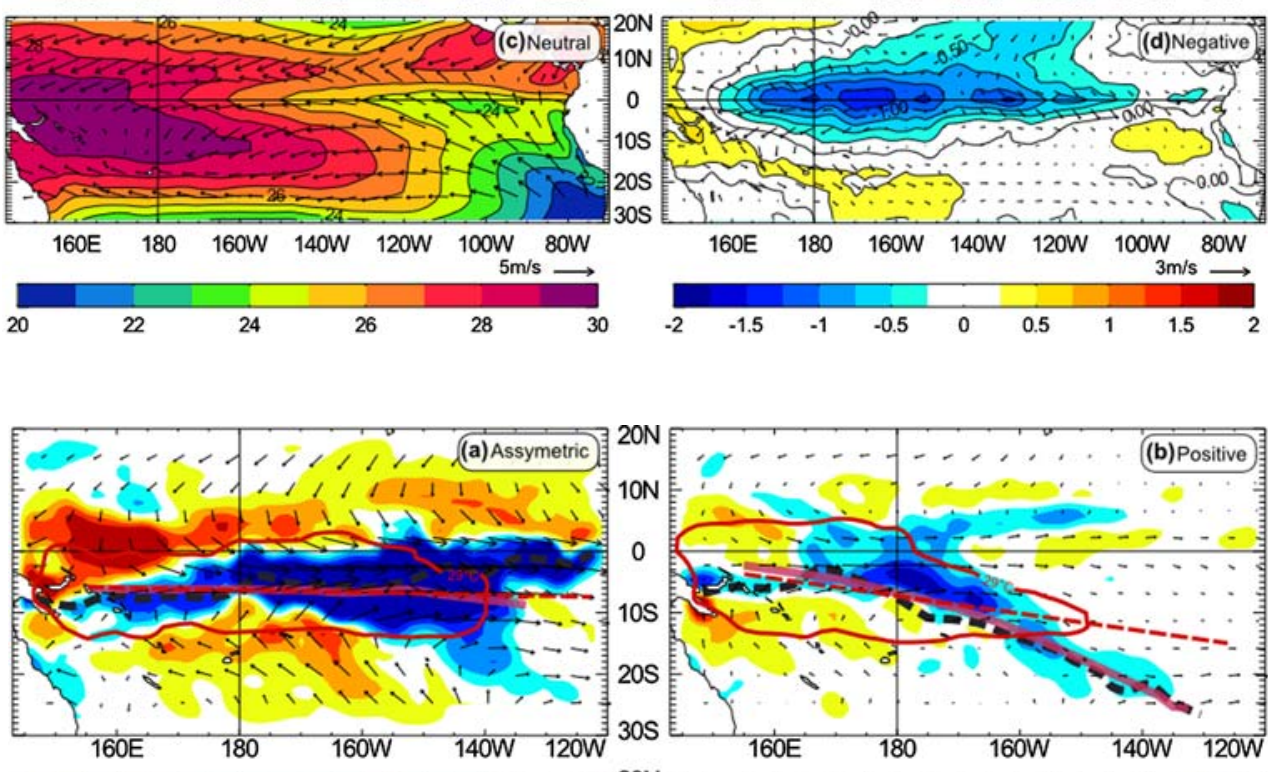

Fig. 8 Moisture divergence at $850 \mathrm{hPa} \vec{\nabla}(q \cdot \vec{v})$ (in $\mathrm{g} \mathrm{kg}^{-1}$ day $^{-1}$; with $q$ specific humidity and $\vec{v}$ winds from ERA40 on the $850 \mathrm{hPa}$ level) for $\mathbf{c}$ the "neutral" class and a, b, d moisture divergence anomalies with respect to the "neutral" class of the "asymmetric", "positive", and "negative" classes,

respectively. The red line is the $29^{\circ} \mathrm{C}$ isotherm, purple line is the SPCZ position, red dashed line is the maximum SST axis, the thick dashed black line points the maximum moisture convergence location and black arrows are winds on the $850 \mathrm{hPa}$ level in (b) and anomalies from the "neutral" winds on other panels
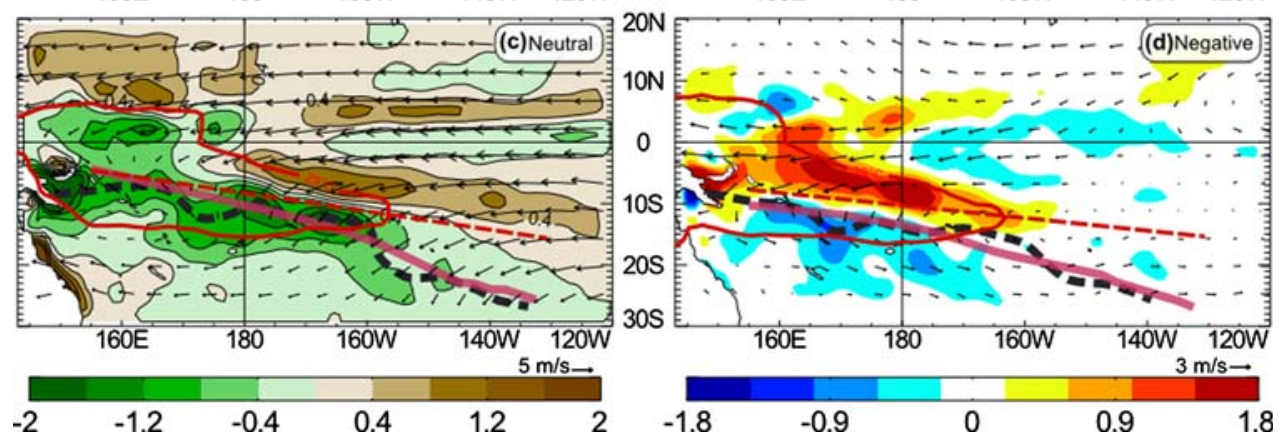

south of the equator (Fig. 7b). This southward shift of the wind response to the equatorially centred SST anomalies is a robust feature of El Niño years in austral summer (Larkin and Harrison 2002) and has been suggested to be fundamentally tied to the annual cycle of insolation through the non-linear response of convective anomalies to the warmest SST migrating south of the equator during austral summer (Spencer 2004; Harrison and Vecchi 1999; Lengaigne et al. 2006). This wind pattern acts to slightly increase wind convergence just north of the mean SPCZ position on both sides of the dateline, resulting in a slight northward shift of the maximum moisture convergence and a subsequent SPCZ shift of about $3^{\circ}$ to the north (Fig. 8b). A similar argument may explain the SPCZ displacement in the "negative" class. In this case, the westward shift of the warm pool associated with the cold SST anomaly (whose maximum is found between $170^{\circ} \mathrm{E}$ and $150^{\circ} \mathrm{W}$, Fig. $7 \mathrm{~d}$ ) generates wind anomalies that increase the divergence north of the mean SPCZ position, displacing the maximum moisture convergence and precipitation axis about $3^{\circ}$ southward (Fig. 8d).

The SPCZ behaviour for the "asymmetric" class is more peculiar. While the SPCZ location east of the dateline is considerably shifted northward, it remains close to its climatological location in its western portion. In addition, even though this cluster contains the two strongest $\mathrm{El} \mathrm{Ni}$ ños of the century (1982/1983 and 1997/1998), it also contains the 1991/1992 El Niño, which is considered as a rather moderate event based on the amplitude of its eastern Pacific SST anomalies. The eastern Pacific warming observed for the "asymmetric" class (Fig. 7a) is dominated by the 1982/1983 and 1997/1998 events, however, the 1991/1992 event does share one characteristic of its equatorial warming with the two strongest El Niño: the three seasons display the largest eastward extension of the warm pool, reaching longitudes east of $160^{\circ} \mathrm{W}$ (Fig. 6b). 
Compared to the "positive" cluster, this larger warm pool expansion of the "asymmetric" cluster results in much stronger and eastward-shifted low-level wind anomalies which are maximum east of the dateline, just south of the equator (Fig. 8a). These anomalies increase considerably the moisture convergence in this region, allowing a displacement of the maximum moisture convergence and precipitation axis of about $10^{\circ}$ to the north.

West of the dateline, the SPCZ is not shifted northward as in the "positive" cluster but remains close to its mean position. During "asymmetric" events, a cold SST anomaly is observed in the north-west Pacific (Fig. 7a). This leads to decreased humidity levels and a strong divergence anomaly that together generate a net divergence of humidity in the north-western ITCZ and around the equator (Fig. 8a), inhibiting precipitation and preventing a northward shift of the SPCZ west of the dateline.

The zonal orientation of the SPCZ therefore occurs when the warm pool also presents a zonal shape being moved southward in the west and eastward around the equator due to the disappearance of the equatorial upwelling in the central part of the basin. During "asymmetric" events, the maximum SST axis is zonally oriented and the maximum precipitation is collocated with it. In the other clusters, the western portion of the SPCZ is anchored to the warmest water while the SPCZ is located slightly poleward of this axis of maximum SST in its eastern end (and on its full length in the "negative" class; Fig. 8). This finding supports the idea that the SPCZ is mainly controlled by SST forcing when it is close to the equator, but also to some extent by interactions with the extra-tropical circulation when it is positioned further from the equator (Kiladis et al. 1989).

Previous studies have shown the importance of distinguishing Niño extremes from other events as they have different physical lifecycles (Lengaigne and Vecchi 2009) and yield different impacts on TC activity (Kim et al. 2009). Here we confirm these studies by showing that different ENSO-related central pacific warming impact differently on the SPCZ position. However, the moderate strength El Niño of 1991/1992 appears in our classification at the side of the two strongest El Niño events illustrating the need to define local indices for regional studies rather than apply a general ENSO index.

\subsection{Relationship between surface wind and SPCZ variability}

The SPCZ location is not only strongly associated with large-scale precipitation, SST and moisture convergence, but also with the dynamical fields. This is illustrated in Fig. 9 by applying a rotated EOF analysis to the surface wind curl (low-level vorticity), in a similar way as for the precipitation (see Fig. 3). The first mode (39\% of the total variance) opposes regions north and south of the mean maximum vorticity axis west of $160^{\circ} \mathrm{W}$ (Fig. 9a), while the second mode (13\% of the total variance) displays a strong cyclonic anomaly east of $170^{\circ} \mathrm{W}$ (Fig. 9b). The PC1-PC2 distribution is also similar to the precipitation one (compare Figs. 3c, 9c) with a first mode opposing "negative" and "positive" years and a second mode dominated by the three "asymmetric" events. The interannual variability of low-level vorticity is therefore intimately tied to precipitation variability in the South Pacific (correlation of PC1s from precipitation and vorticity is 0.95 ). The same analysis applied to the surface wind, the surface wind divergence or $500 \mathrm{hPa}$ vertical velocity gives very similar results (not shown), suggesting more generally that the dynamical fields are strongly tied to the SPCZ variability in this region.

Figure 10 displays the surface wind patterns in the South Pacific for each of the four classes arising from the SPCZ classification. We begin with the 'neutral' class, as it presents a wind structure close to the climatological one in the South Pacific (Fig. 10c). Convective precipitation in the SPCZ region is essentially tied to surface wind convergence. This convergence arises from the confluence of the trade winds in the eastern SPCZ, while, in its western part, it results from the convergence of Australian monsoon winds (north of the SPCZ) and the trade winds (south of it). The transition between these two different dynamical regimes within the SPCZ is represented by the confluence point (CP), defined as the easternmost point at any latitude reached by monsoon westerlies in the South Pacific (adapting the original definition that Chan and Evans (2002) used in the Northwest Pacific ITCZ). Interestingly, the CP defined in this way is, for all DJF seasons, located on the SPCZ line. The monsoon trough, defined as the region of minimum surface pressure, is characterised by "moist, southwest monsoon flows on its equatorward side and easterly trades on its poleward side" (Chu 2004). Within the monsoon trough region is found the monsoon shear line (MSL) where the maximum cyclonic vorticity is found as the encounter between the eastward monsoon winds and westward trade winds results in strong meridional wind shear. East of the $\mathrm{CP}$, cyclonic vorticity is associated with curving trade winds and is weaker: the $\mathrm{CP}$ longitude thus marks the eastern boundary of the MSL. The $\mathrm{CP}$ also appears to be a good proxy for the strength of the MSL since the intensity of the vorticity averaged along the axis of the MSL is strongly correlated with the CP longitude (0.89). In contrast to the north-west Pacific ITCZ where the maximum cyclonic vorticity is found to be collocated with the maximum of precipitation and as been used to defined the ITCZ axis (Chan and Evans 2002), the maximum cyclonic vorticity in the SPCZ lies $6^{\circ}$ south of 
Fig. 9 a, b First two EOFs of ERA40 DJF vorticity on the period 1979-2002, and c coordinates of each year on the two-first modes (colors remind the class to which each season belongs, see Sect. 3.1 and Fig. 4). The dashed line marks the mean maximum vorticity axis
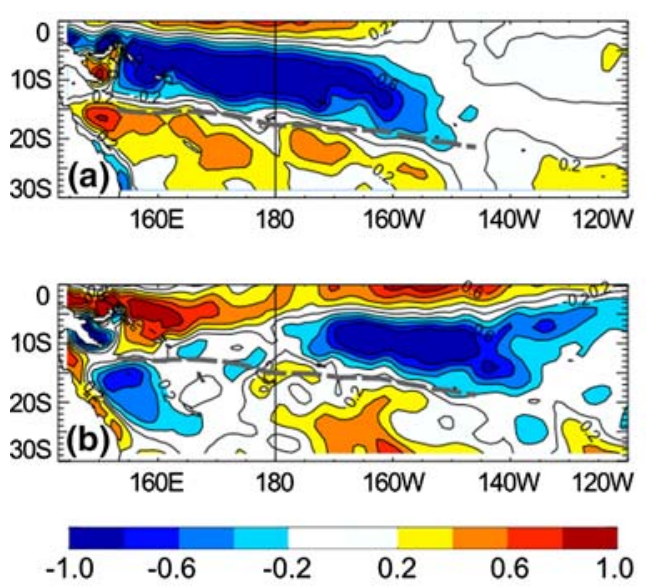

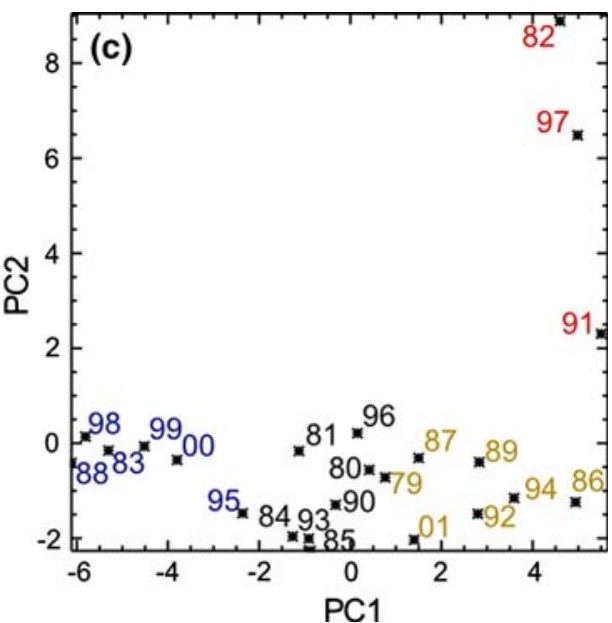

the maximum precipitation that is collocated with the zero of the vorticity field (Table 5; Fig. 10). This dynamical organisation described from climatological fields is also valid in interannual variations. The displacement of the zero and maximum vorticity axes are strongly tied to the interannual evolution of the SPCZ on its western and eastern part (Table 5) showing that the MSL variability is closely related to the SPCZ variability. From "negative" to "asymmetric", the MSL increases in strength while the CP is displaced north-eastward. During "asymmetric" years, the SPCZ is almost entirely defined by a monsoon type convergence zone, and low-level vorticity within the monsoon trough increases considerably east of the dateline (Fig. 10a).

\section{Importance of the position of the SPCZ for tropical cyclogenesis}

In the previous section, surface wind variability has been shown to be strongly connected to the displacement of the SPCZ. TC genesis is known to be dependent on large scale dynamical and thermodynamical fields and surface cyclonic vorticity is one of the variables that favour the genesis of TCs (Gray 1979). In this section, we will investigate the relationship between the interannual variability of the SPCZ and the interannual variability of TC genesis geography.

\subsection{TC genesis variability in the South Pacific}

The mean position of TC genesis $^{2}$ for each season derived from the Joint Typhoon Warning Center (JTWC) dataset

\footnotetext{
${ }^{2}$ Genesis is defined as the first position of a Tropical Depression in the JTWC database that will develop 1-min averaged winds $>17 \mathrm{~m} / \mathrm{s}$.
}

provides a first look at the interannual variability of the genesis location in the South Pacific (Fig. 11). It appears that the 3 years forming the SPCZ "asymmetric" cluster defined in the previous section lare neatly separated from the rest as their mean longitude of genesis is located east of the dateline. In addition, "negative" years display a more southern location in their mean genesis latitude than do the other years. In contrast, no clear difference in the mean genesis location is observed between "neutral" and "positive" years with regard to their mean genesis position.

This first observation is extended by analysing composites of genesis density maps of the Southern Hemisphere cyclonic seasons (July year $n$ to June year $n+1$ ). Note that most TCs form during the December-March period and very similar results are obtained when considering only the TCs formed during this period instead of the full cyclonic season. Density maps of genesis are obtained by generating Probability Density Functions computed from anisotropic Gaussian functions, with an associated standard deviation in zonal and meridional directions, respectively, of $1.5^{\circ}$ and $3^{\circ}$ following the method used by Ramsay et al. (2008). Each genesis point is spatially extended following this Gaussian shape and density maps for each cyclonic season are obtained by summing the contribution of each Gaussian on a $2.5^{\circ} \times 2.5^{\circ}$ grid. On average, the TC genesis distribution is almost zonal (between $10^{\circ} \mathrm{S}$ and $15^{\circ} \mathrm{S}$ ) and extends from the northern coast of Australia to $160^{\circ} \mathrm{W}$ (Fig. 12c). For each SPCZ class, the genesis region (black dashed line) is located just south of the SPCZ position. "Asymmetric" and "positive" years both display increased cyclogenesis in the Tuvalu region and decreased cyclogenesis in the Coral Sea. Opposite variations are found for "negative" years in these regions. If the genesis patterns are similar west of the dateline for the "positive" and "asymmetric" classes, they strongly differ east of it. A large positive anomaly of 


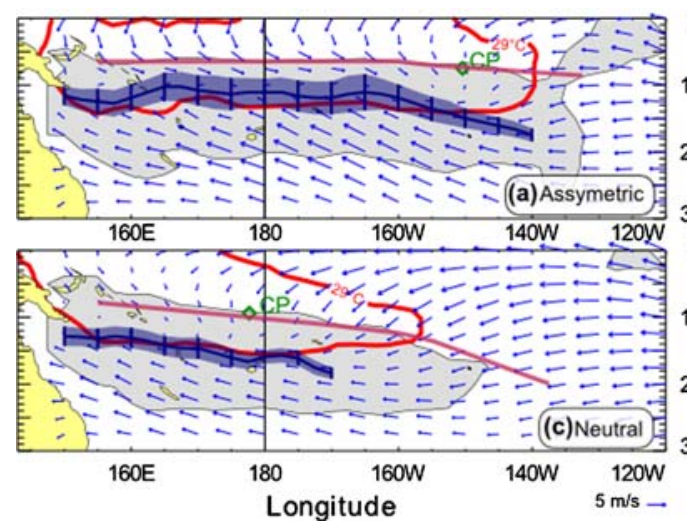

Fig. 10 Composite DJF surface fields related to the SPCZ for the four classes: a "asymmetric", b "positive", c "neutral" and d "negative" class. The purple line is the SPCZ composite position; blue vectors represent the surface wind field; region of cyclonic relative vorticity of surface winds is shaded in grey, the blue line points the maximum vorticity axis and its thickness represents the

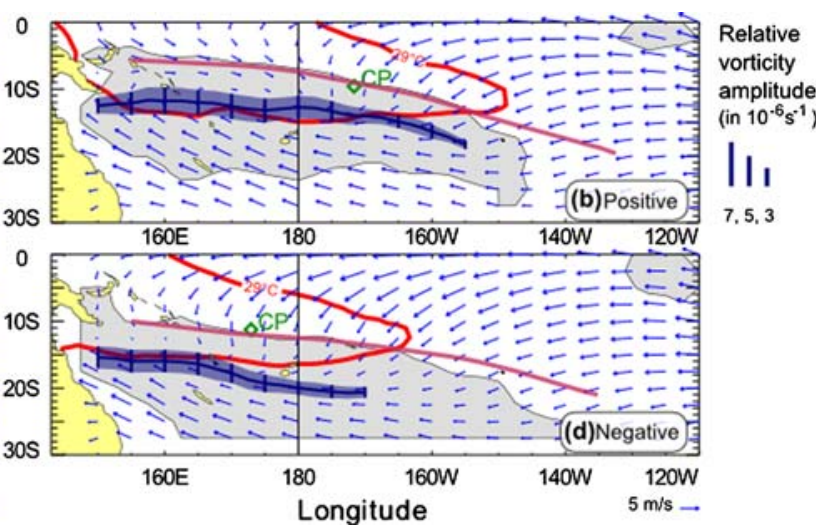

magnitude of the vorticity along the monsoon shear line (MSL); red line is the $29^{\circ} \mathrm{C}$ isotherm of SST; diamond indicates the location of the confluence point $(C P)$ defined as "the point of the SPCZ where winds change from an eastward component to a westward component". Note that for consistency all fields on this figure are from ERA40 (except SST from HadISST) cyclogenesis in the central Pacific (Polynesia region), is indeed observed during "asymmetric" years and contrasts with the weak anomaly found in the "positive" class (Fig. 12b).

\subsection{Interannual variability of TC genesis favourable parameters}

Tropical cyclones have a tendency to form in regions with favourable large-scale environmental parameters: high oceanic heat content (OHC), low-level cyclonic vorticity, high humidity in the mid-troposphere and low vertical wind shear within the troposphere. Several empirical indices have been developed to understand how these dynamical and thermodynamical variables are coupled together to define regions where TCs will be allowed to form. Gray (1979) first developed a seasonal genesis potential index (SGP) followed by Emanuel and Nolan (2004) who developed another genesis potential index (GPI). Both indices are constructed as an empirical combination of all favourable variables fitted to the observed numbers of genesis globally. Royer et al. (1998) simplified the thermal potential of the SGP index by considering only convective precipitation (to allow its use in climate change runs of general circulation models) and named it the convective seasonal genesis potential index (CSGP, see "Appendix"). Compared to the GPI and SGP, the CSGP was found to best reproduce both the climatological patterns and the interannual variations of TC genesis in the South Pacific (Menkes et al. 2009). In particular, it is almost able to reproduce the observed location of maximum cyclogenesis to the south of the SPCZ (Fig. 13c) while other indices locate the maximum of genesis right on the SPCZ (not shown). The CSGP is also able to reproduce the broad features of genesis anomaly patterns associated to the four classes of SPCZ variability (compare Figs. 12a, b, d, 13a, b, d): during the "negative" class, the negative (positive) anomaly north (south) of the SPCZ is well reproduced, positive anomalies for the "positive" and "asymmetric" classes are also quite well reproduced, the main shortcoming comes from the representation of the negative anomaly of genesis in the "Coral Sea" for the two latter classes that is not reproduced by the CSGP with sufficient intensity (and neither by SGP and GPI).

Here we build on the terms involved in the calculation of the CSGP to understand the link observed between TC genesis and SPCZ position interannually. Three terms are involved in the CSGP calculation: the "dynamic potential" is composed of (1) $I_{\mathrm{S}}$, the calculation of which involves the vertical shear of winds between 950 and $200 \mathrm{hPa}$, and (2) $I_{\zeta}$, which involves the relative vorticity at $950 \mathrm{hPa}$. The "convective potential" $C_{\text {pot }}$ is only represented by (3) the convective precipitation term as a measure of the enthalpy available for the cyclone (see "Appendix" for details on these three terms calculation). In the "neutral" years composite of Fig. 14, we note that: (1) the region of minimum vertical shear (shear $<16 \mathrm{~m} \mathrm{~s}^{-1} / 750 \mathrm{hPa}$ ) is observed along the SPCZ $\left(10^{\circ} \mathrm{S} / 180^{\circ}-25^{\circ} \mathrm{S} / 120^{\circ} \mathrm{W}\right)$ and west of the $\mathrm{CP}$ a broader region of very low vertical shear (lower than $9 \mathrm{~m} \mathrm{~s}^{-1} / 750 \mathrm{hPa}$ ) is observed in the $7^{\circ} \mathrm{S}-15^{\circ} \mathrm{S} /$ $145^{\circ} \mathrm{E}-180^{\circ}$ region. (2) The SPCZ marks the north-eastern limit of the region where favourable cyclonic vorticity can be found. (3) High convective precipitation is localised around the SPCZ position. The organisation of favourable parameters with respect to the SPCZ position described for the "neutral" class is also valid for the three other 
Table 5 Mean distance and correlation between the zero and maximum vorticity axes to the SPCZ position in latW and latE regions

\begin{tabular}{lcc}
\hline & In lat $\mathrm{W}$ & In lat E \\
\hline SPCZ and zero vorticity axis & & \\
Mean distance $\left({ }^{\circ}\right.$ lat $)$ & 0.7 & -0.6 \\
Correlation & 0.93 & 0.91 \\
SPCZ and max vorticity axis (MSL) & & \\
Mean distance $\left({ }^{\circ}\right.$ lat) & -5.7 & -6.2 \\
Correlation & 0.88 & 0.82 \\
\hline
\end{tabular}

All correlations significant at the $95 \%$ level with respect to a twotailed Student's $t$ test

composites (Fig. 14a, b, d). Figure 14 shows that the overlap area of positive vorticity, shear values lower than $9 \mathrm{~m} \mathrm{~s}^{-1} / 750 \mathrm{hPa}$ and convective precipitation $>4 \mathrm{~mm} /$ day is always found just south of the SPCZ position and west of the CP. The region of observed TC genesis (thick black dashed line) is shown to match this overlap region, with $67 \%$ of observed TCs in the South Pacific forming inside this region. The proportion increases to $87 \%$ when considering the $16 \mathrm{~m} \mathrm{~s}^{-1} / 750 \mathrm{hPa}$ vertical shear isoline instead of the $9 \mathrm{~m} \mathrm{~s}^{-1} / 750 \mathrm{hPa}$. Chand and Walsh (2009) note that "TC genesis over the Fiji region is highly favoured for environmental vertical wind shear $<8 \mathrm{~m} / \mathrm{s}$ " (calculated between 850 and $200 \mathrm{hPa}$ levels); this value compares to our value of $9 \mathrm{~m} / \mathrm{s}$ (calculated between 950 and $200 \mathrm{hPa}$ levels) even if our calculation is based on DJF means while their calculation is based on daily composites.

The regions of greater variability for cyclogenesis in the different SPCZ classes are identified in Fig. 12. These are the "Polynesia" $\left(165^{\circ} \mathrm{W}-130^{\circ} \mathrm{W} / 5^{\circ} \mathrm{S}-20^{\circ} \mathrm{S}\right)$, "Tuvalu" $\left(165^{\circ} \mathrm{E}-165^{\circ} \mathrm{W} / 5^{\circ} \mathrm{S}-13^{\circ} \mathrm{S}\right)$, "Fiji" $\left(165^{\circ} \mathrm{E}-165^{\circ} \mathrm{W} / 13^{\circ} \mathrm{S}-\right.$ $\left.25^{\circ} \mathrm{S}\right)$ and "Coral Sea" $\left(143^{\circ} \mathrm{E}-165^{\circ} \mathrm{E} / 10^{\circ} \mathrm{S}-20^{\circ} \mathrm{S}\right)$ regions. To identify the large scale parameters associated with genesis variability, we compare the TC genesis number per region with the CSGP and the three terms composing it averaged over each of the four regions (Fig. 15). The latter three terms are normalised by their mean magnitude over the South Pacific domain $\left(143^{\circ} \mathrm{E}-120^{\circ} \mathrm{W} / 0-30^{\circ} \mathrm{S}\right)$ to allow for comparison both between terms and between regions. We first note that the "Polynesia" region is affected by cyclogenesis only during the three "asymmetric" years. This observation is reasonably well reproduced by the CSGP and main variability appears to be due to the vorticity and thermal potential terms (Fig. 15). The zonal orientation of the SPCZ during "asymmetric" years brings deep convection to the central Pacific and allows the eastward extension of background cyclonic vorticity in the "Polynesia" region (Fig. 14).

In the "Tuvalu" region, no cyclones are formed during "negative" years despite favourable shear and thermodynamical conditions. In this case, the background anticyclonic vorticity due to the southward SPCZ shift has produced locally unfavourable conditions responsible for this absence of genesis (Fig. 15b). From "neutral" to "asymmetric" years, an increase of TC genesis number is observed; the CSGP catches an increase of favourable conditions but overestimates the observed variability for the "positive" and "asymmetric" classes. All CSGP terms vary accordingly with the observed increase of cyclogenesis but the vorticity term appears to be the primary driver of the CSGP increase for the "positive" and "asymmetric" classes. We remark that the 1996/1997 season is outside of the "neutral" group with regards to TC genesis number and degrades the relationship (Fig. 15a). During this year, TCs are formed late in the season ( 2 in March, 2 in April, 1 in May and 1 in June 1997). These late geneses with respect to a standard season are probably related to the onset of the 1997/1998 strong El Niño event in March 1997 and are responsible for the peculiar behaviour of this cyclonic season.

In the "Coral Sea" region, vorticity is always favourable for TC genesis. Indeed the region lies at the heart of the monsoon trough eastern portion that experiences a persistent horizontal shear between monsoon and trade winds. The genesis density difference between "negative"-"neutral" and "positive"-"asymmetric" years observed in Fig. 12 seems to be mostly sensitive to the thermodynamical potential that shows the greatest relative modification. However, little confidence can be given to this result as all three indices show poor skill in reproducing the interannual variability of TC genesis in this region.
Fig. 11 Mean position of cyclogenesis for each year in the South Pacific region $\left(143^{\circ} \mathrm{E}-\right.$ $80^{\circ} \mathrm{W} / 0-30^{\circ} \mathrm{S}$ ): year $n$ stands for the Southern Hemisphere cyclonic season from July year $n$ to June year $n+1)$. Overall mean longitude and latitude given by the dashed lines

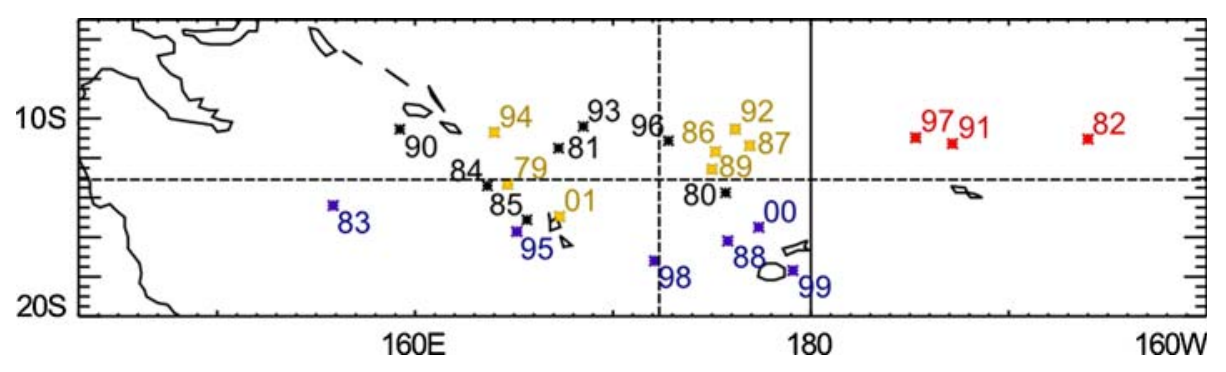




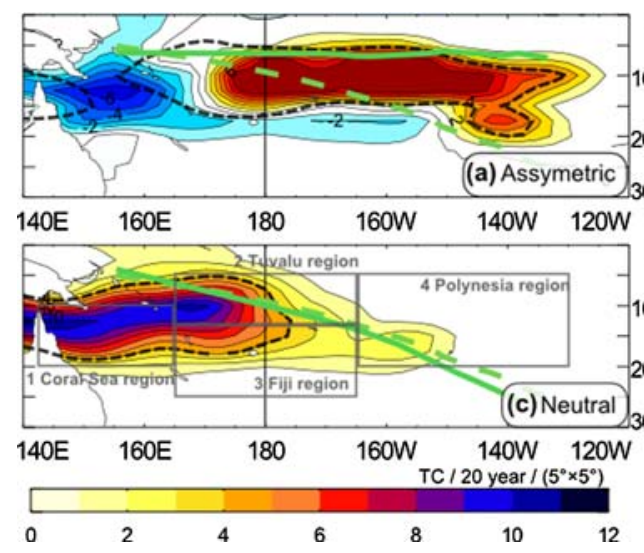

Fig. 12 c "Neutral" class TC genesis density (in number of genesis per 20 years and per $5^{\circ} \times 5^{\circ}$ boxes); rectangles delimitate the different regions discussed in the text: 1 Coral Sea, 2 Tuvalu, 3 Fiji and 4 Polynesia. a "Asymmetric", b "positive", d "negative" composites of TC genesis density anomaly with respect to the
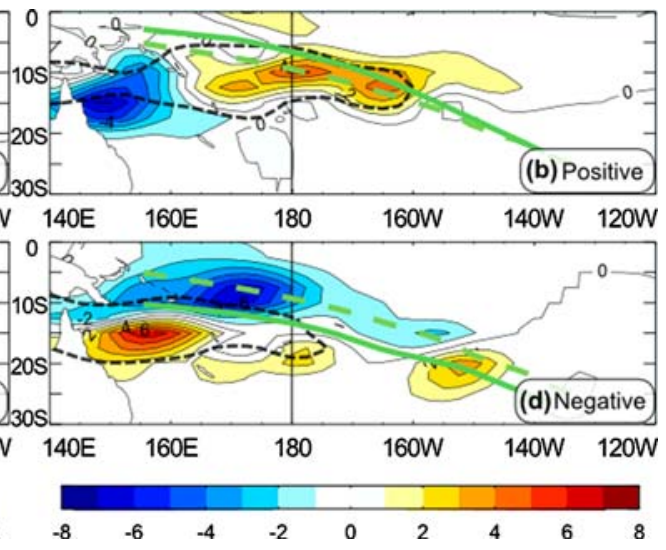

"neutral" case; the thick dashed contour is the isoline four TC/ 20 years $/\left(5^{\circ} \times 5^{\circ}\right)$ of TC genesis density. Climatological GPCP SPCZ (green dashed line) and composite SPCZ (green line) are reported on each map
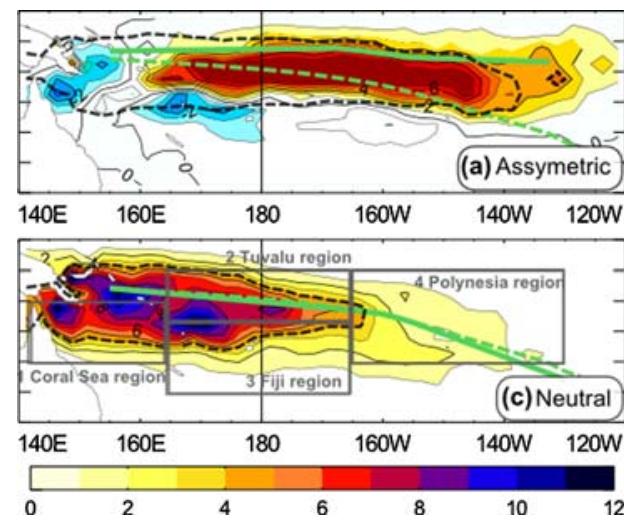

Fig. 13 Same as Fig. 12 but for the composites of the convective seasonal genesis potential index $(C S G P)$ for the four classes. Units of the index are fitted to the global TC number and can be read as formation of TC per $5^{\circ}$ lon-lat boxes per 20 year. c "Neutral" class genesis density, a "asymmetric", b "positive", d "negative" years

In the "Fiji" region, vorticity is also always favourable and even if increasing from "negative" to "asymmetric" years, the genesis of TCs follows an inverse tendency which is to be related to the thermal potential (and to a lesser extent to wind shear) which decreases from "negative" to "asymmetric" years (Fig. 15). We remark that relatively to other regions, the CSGP always tends to overestimate the number of genesis in "Fiji" and "Coral Sea" regions.

Conducting a similar analysis on the different terms composing the GPI of Emanuel and Nolan (2004) yields very similar results (not shown) about the relative importance of dynamical and thermodynamical terms to constrain the interannual variability of cyclogenesis.

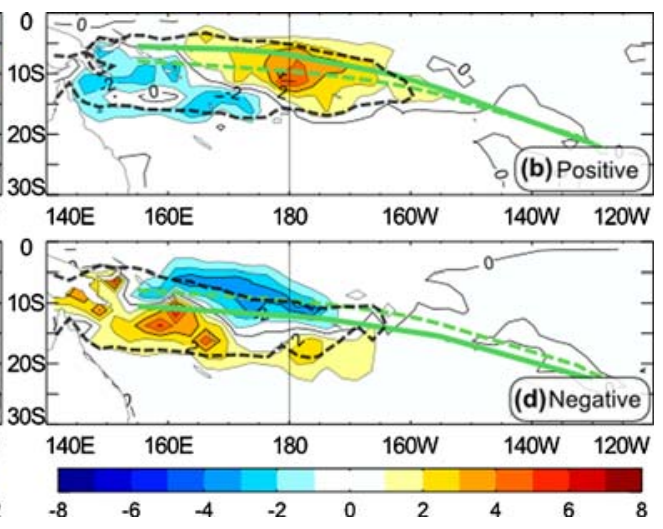

composites of genesis density anomaly with respect to the "neutral" case; the thick dashed contour is the four TC/20 years $/\left(5^{\circ} \times 5^{\circ}\right)$ composite isoline. Climatological ERA40 SPCZ (green dashed line) and composite SPCZ (green line) are reported on each map

\section{Summary and conclusions}

This study investigates the interannual variability of the SPCZ and its influence on TC genesis using satellite data and ERA40 reanalysis over the 1979-2002 period.

An AHC method allows four characteristic structures of the interannual position of the SPCZ in austral summer to be identified. A "neutral" class gathers years when the SPCZ is close to the climatological position, while a "negative" ("positive") class gathers years when the SPCZ is displaced by about $3^{\circ}$ south (north) of its climatological position. These three classes displace a similar diagonal orientation of the SPCZ position. In contrast, the fourth class (the "asymmetric" class), that only contains 3 years 


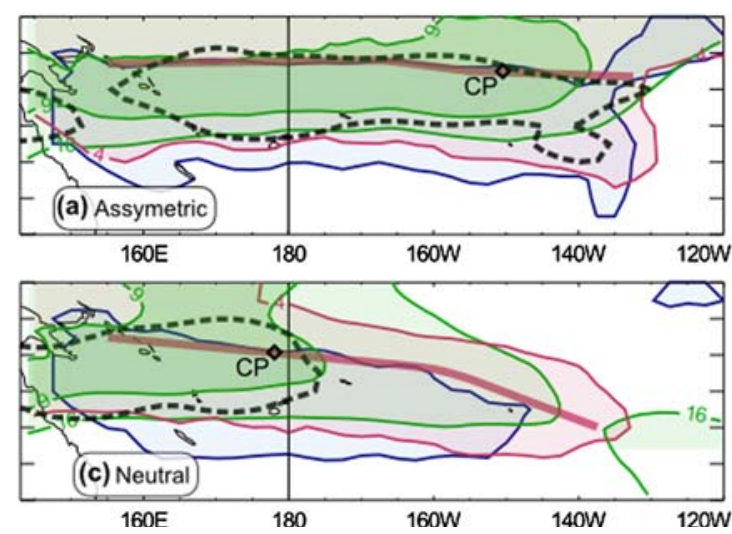

Fig. 14 Composites of ERA40 terms involved in the calculation of the CSGP; green 9 and $16 \mathrm{~m} \mathrm{~s}^{-1} / 750 \mathrm{hPa}$ contours of vertical wind shear (between 950 and $200 \mathrm{hPa}$ ), blue $0 \mathrm{~s}^{-1}$ contour of surface relative vorticity and purple $4 \mathrm{~mm} /$ day contour of convective

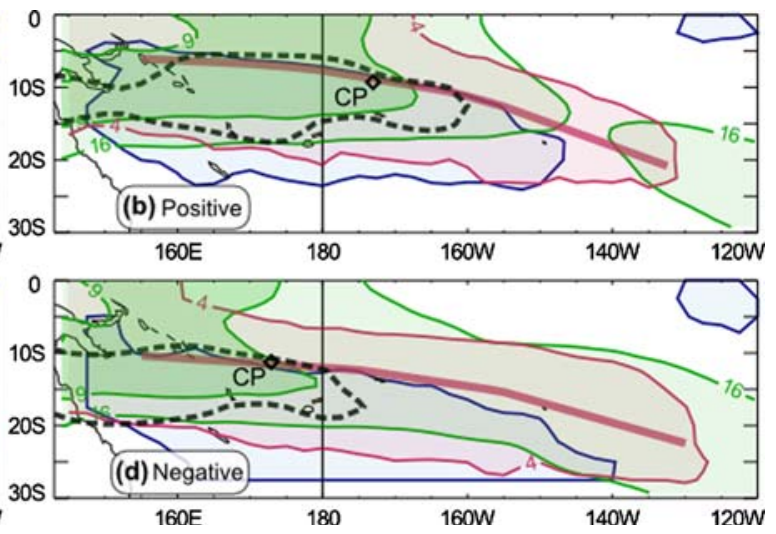

precipitation; purple line SPCZ composite position and the thick dashed contour reproduces the four $\mathrm{TC} / 20$ years $/ 5^{\circ}$ isoline of $\mathrm{TC}$ genesis density of Fig. 12

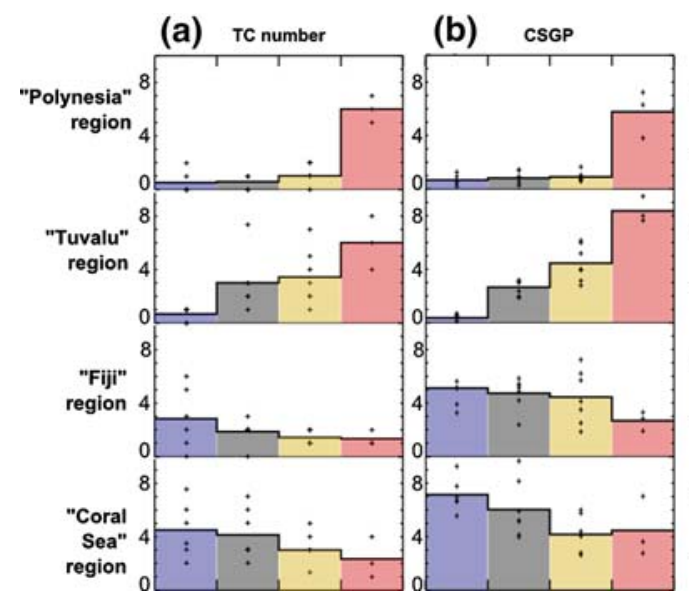

Fig. 15 a Averaged TC genesis number and $\mathbf{b}$ value reconstructed from the CSGP per region and per class [from left to right: "negative" (blue), "neutral" (black), "positive" (yellow) and "asymmetric" $($ red $)$ ] and comparison with the terms involved in the calculation of the CSGP (non-dimensional units): c vorticity term $I_{\zeta}$, d wind shear

(the extremes 1982/1983 and 1997/1998 El Niño events and the moderate 1991/1992 El Niño event) displays an SPCZ that is zonally oriented located around $6^{\circ} \mathrm{S}$.

This study confirms that ENSO phenomenon strongly modulates the SPCZ movement, as first discussed by Trenberth (1976) and in agreement with Folland et al. (2002). More precisely, the SPCZ location east (west) of the dateline is strongly related to the variability of the equatorial SST in the central Pacific (near the dateline). SST rise (drop) in these equatorial regions increase (decrease) low-level moisture transport just south of the equator and the vertical instability of the atmosphere, allowing deep convection to occur north (south) of its mean position. This mechanism is particularly effective during the two extreme 1982/1983 and 1997/1998 El Niños, as
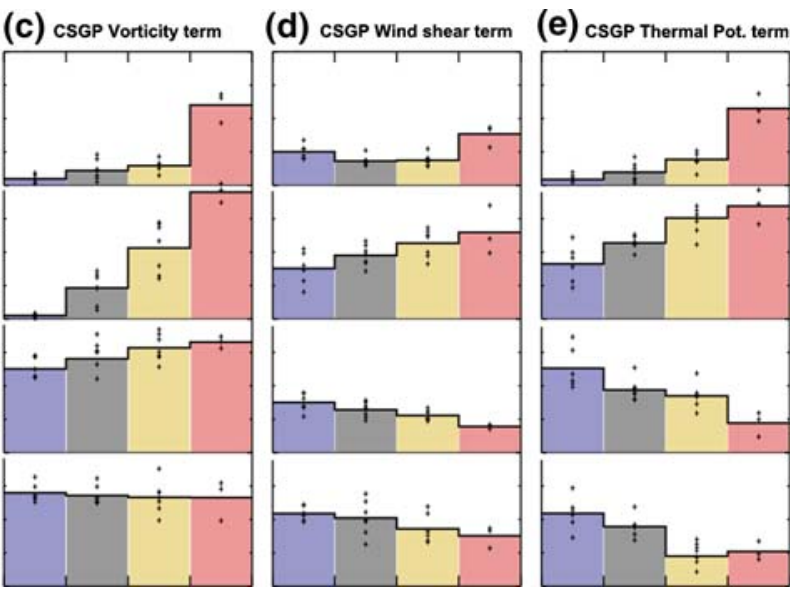

term $I_{\mathrm{S}}$ and $\mathbf{e}$ thermodynamical term $C_{\text {pot }}$. Each term is normalised by its average magnitude in the South Pacific domain $\left(143^{\circ} \mathrm{E}-120^{\circ} \mathrm{W} / 0_{-}\right.$ $30^{\circ} \mathrm{S}$ ) to allow comparison between terms and between regions. Each plus marks the value of an individual year forming the class for an evaluation of its homogeneity

well as during the moderate 1991/1992 El Niño, when the eastern edge of the equatorial warm-pool is displaced east of $160^{\circ} \mathrm{W}$. This considerably increases the moisture transport south of the equator, shifting the SPCZ location east of the dateline by more than $10^{\circ}$ north of its climatological position. Moreover, the western part of the SPCZ is displaced to the south mainly due to a cold SST anomaly and a surface divergence in the north-western Pacific suppressing the ITCZ here during "asymmetric" years while SPCZ and ITCZ are merged along the equator during "positive" years.

The SPCZ location is found to be a good indicator of the changes to atmospheric circulation in the South Pacific. From year-to-year, the SPCZ location is collocated with the zero relative vorticity axis at low levels, while the MSL 
(i.e., the maximum vorticity axis) lies $6^{\circ}$ south of the SPCZ position. In addition, both the eastward extension of monsoon wind and the intensity of the MSL increase as the SPCZ is displaced northward. During "asymmetric" years, the SPCZ can even be almost entirely defined by a monsoon type convergence regime and the vorticity increases considerably east of the dateline. Because the SPCZ position summarizes large scale dynamic and thermodynamic fields, it is also shown to be a good indicator of the geography of cyclogenesis in the South Pacific. Genesis indices such as the CSGP allow to study the main factors favouring or limiting cyclogenesis. Based on analysis of these factors, we conclude that the anticyclonic vorticity of low-level winds just north of the SPCZ prevents cyclogenesis in this region while low wind shear within the troposphere, vertical instability of the troposphere (depicted as deep convective precipitations) and cyclonic vorticity of low-level wind combine just south of the SPCZ to allow TCs to develop. Cyclogenesis interannual variability in the region is shown to follow SPCZ movement in its north-south displacement and to preferentially occur within $10^{\circ}$ south of the SPCZ location. Four distinct spatial patterns are depicted in the TC observations in relation to the SPCZ classes. These patterns are also correctly reproduced by the CSGP (but also by the GPI and SGP indices). Even if the actual TC genesis numbers cannot be reproduced by these indices due to the intrinsic high level of stochasticity in TC genesis in that region (see Jourdain et al. 2009; Menkes et al. 2009 for a detailed discussion), indices do reproduce the "asymmetric" and "negative" patterns pretty well, but do not reproduce the decrease of cyclogenesis in the Coral Sea during "positive" and "asymmetric" phases.

Our approach provides a means of demonstrating that cyclogenesis east of the dateline (in the vicinity of French Polynesia) is only likely to occur when the SPCZ displays a zonal orientation while this observation was previously attributed to El Niño years in general. During the years of "asymmetric" SPCZ, the strong northward displacement of the SPCZ east of the dateline generates a strong positive cyclonic vorticity in this region, favouring cyclogenesis. This zonal orientation of the SPCZ and its associated increased cyclogenesis in the central Pacific depends more strongly on the west-east displacement of the eastern edge of the warm pool than on the SST anomaly magnitude depicted by the Niño 3 SST index. While the 1991/1992 El Niño is considered as a moderate El Niño based on the Niño 3 SST index, our results show that its SPCZ evolution behaves similarly to the extreme 1982/1983 and 1997/1998 El Niño events because these three events display the largest SST anomalies east of the dateline and hence the largest eastward shift of the equatorial warm pool. While Kim et al. (2009) show that the characteristics of the boreal summer equatorial Pacific warming leads to different impacts on the cyclogenesis in the Atlantic basin, we here show that similar characteristics of the austral summer equatorial Pacific warming have to be taken into account when addressing the interannual variability of cyclogenesis in the south-west Pacific. This sensitivity of SPCZ variations and related cyclogenesis in the central Pacific to the equatorial warm pool extent suggests the possibility of additional predictability of cyclogenesis in this region beyond that associated with just predicting the occurrence of El Niño. However, predictions of the details of the pattern of the SST anomalies during El Niño have not yet been demonstrated.

The clarification between cyclogenesis and SPCZ organisation brought by this study may also bring light to the large discrepancies found in the SPCZ region of projected cyclogenesis modifications under climate change scenarios (Caron and Jones 2008; Royer and Chauvin 2009). In this vein, future investigations will require taking into account the modifications in the organisation and interannual variability of the SPCZ simulated by GCMs for future climate.

Acknowledgments This work was supported by the French "Agence Nationale de la Recherche" (ANR) through the programme Cyclones\&Climat ANR-06-VULN-002-01. The authors would like to thank ECMWF for making the ERA40 reanalyses available, the Joint Typhoon Warning Center (JTWC) and the National Hurricane Center for the use of their TC best track data as well as the U.K. Met. Office for use of the HadISST dataset. We acknowledge three anonymous reviewers and Daniel Nethery for their useful comments, which lead to improvements to the present manuscript.

\section{Appendix}

Details on the calculation of the convective seasonal genesis parameter

Royer et al. (1998) modified the gray convective seasonal parameter index (Gray 1979) to avoid the use of fixed threshold of SST, which prevented it from being used in GCM climate simulations. They suggested replacing the thermal potential with a convective potential $C_{\text {pot }}$ directly linked to the convective precipitation of the model:

$$
\mathrm{CSGP}=\underbrace{\left(|f| \times I_{\zeta} \times I_{\mathrm{S}}\right)}_{\text {DynamicPot }} \times \underbrace{\left(k \times P_{\mathrm{c}}\right)}_{\text {ConvectivePot }}
$$

Here:

- $f$ is the Coriolis parameter (in $10^{-5} \mathrm{~m} \mathrm{~s}^{-1}$ ),

- $I_{\varsigma}=\varsigma_{\mathrm{r}} \cdot \frac{f}{|f|}+5$ where $\zeta_{\mathrm{r}}$ is the low level relative vorticity at $950 \mathrm{hPa}\left(\right.$ in $10^{-6} \mathrm{~s}^{-1}$ ),

- $I_{\mathrm{S}}=\left(\frac{\delta V}{\delta P}+3\right)^{-1}$ is the inverse of the vertical shear of the horizontal wind between 950 and $200 \mathrm{hPa}$, (in $\mathrm{m} \mathrm{s}^{-1} / 750 \mathrm{hPa}$ ), 
- $P_{\mathrm{c}}$ is the convective precipitation term of the model,

- $k$ is a constant dependent on the model.

\section{References}

Adler RF, Huffman GJ, Chang A, Ferraro R, Xie P, Janowiak J, Rudolf B, Schneider U, Curtis S, Bolvin D, Gruber A, Susskind J, Arkin P (2003) The version 2 Global Precipitation Climatology Project (GPCP) monthly precipitation analysis (1979present). J Hydrometeor 4:1147-1167

Ashok K, Behera SK, Rao SA, Weng H, Yamagata T (2007) El Niño Modoki and its possible teleconnection. J Geophys Res 112:C11007. doi:10.1029/2006JC003798

Basher RE, Zheng X (1995) Tropical cyclones in the Southwest Pacific: spatial patterns and relationships to southern oscillation and sea surface temperature. J Clim 8:1249-1260

Caron LP, Jones CG (2008) Analysing present, past and future tropical cyclone activity as inferred from an ensemble of coupled global climate models. Tellus 60A:80-96

Chan SC, Evans JL (2002) Comparison of the structure of the ITCZ in the west Pacific during the boreal summers of 1989-93 using AMIP simulations and ECMWF reanalysis. J Clim 15:35493568

Chand SS, Walsh KJ (2009) Tropical cyclone activity in the Fiji region: spatial patterns and relationship to large scale circulation. J Clim 22:3877-3893. doi:10.1175/2009JCLI2880.1

Chu PS (2004) ENSO and tropical cyclone activity. Hurricanes and typhoons, past, present and future. Columbia University Press, New York, pp 297-332

Emanuel KA, Nolan DS (2004) Tropical cyclone activity and global climate. In: Proceedings of the 26th conference on hurricanes and tropical meteorology. American Meteorological Society, Miami, FL, pp 240-241

Evans JL, Allan RJ (1992) El Niño/southern oscillation modification to the structure of the monsoon and tropical cyclone activity in the Australasian region. Int J Clim 12:611-623

Folland CK, Renwick JA, Salinger MJ, Mullan AB (2002) Relative influence of the interdecadal Pacific oscillation and ENSO on the South Pacific Convergence Zone. Geophys Res Lett 29:1643. doi: 10.1029/2001GL014201

Gouriou Y, Delcroix T (2002) Seasonnal and ENSO variations of sea surface salinity and temperature in the South Pacific Convergence Zone during 1976-2000. J Geophys Res 107:8011. doi: 10.1029/2001JC000830

Gray WM (1979) Hurricanes: their formation, structure and likely role in the tropical circulation. In: Shaw DB (ed) Meteorology over the tropical oceans. Roy Meteor Soc, London, pp 155-218

Harrison DE, Vecchi GA (1999) On the termination of El Niño. Geophys Res Lett 26(11):1593-1596

Hastings PA (1990) Southern Oscillation influence on tropical cyclone activity in the Australian/south-west Pacific region. Int J Climatol 10:291-298

Holland GJ, McBride JL, Nicholls N (1988) Australian region tropical cyclones and the greenhouse effect. In: Greenhouse planning for climate change, pp 438-455

Jourdain NC, Marchesiello P, Menkes CE, Lefevre J, Vincent EM, Lengaigne M, Chauvin F, Royer JF (2009) Mesoscale simulation of tropical cyclones in the South Pacific: climatology and interannual variability. J Clim (submitted)

Kiladis GN, Storch HV, Loon HV (1989) Origin of the South Pacific Convergence Zone. J Clim 2:1185-1195

Kim HM, Webster PJ, Curry JA (2009) Impact of shifting patterns of pacific ocean warming on north Atlantic tropical cyclones. Science 325:77-80. doi:10.1126/science.1174062
Kuleshov Y, Qi L, Fawcett R, Jones D (2008) On tropical cyclone activity in the Southern Hemisphere: trends and the ENSO connection. Geophys Res Lett 35:L14S08. doi:10.1029/2007 GL032983

Larkin NK, Harrison DE (2002) ENSO warm (El Niño) and cold (La Niña) event life cycles: ocean surface anomaly patterns, their symmetries, asymmetries, and implications. J Clim 15:11181140

Lengaigne M, Vecchi GA (2009) Contrasting the termination of moderate and extreme El Niño events in coupled GCM. Clim Dyn. doi:10.1007/s00382-009-0562-3

Lengaigne M, Boulanger JP, Menkes C, Spencer H (2006) Influence of the seasonal cycle on the termination of El Niño events in a coupled general circulation model. J Clim 19:1850-1868. doi: 10.1175/JCLI3706.1

Lintner BR, Neelin JD (2008) Eastern margin variability of the South Pacific Convergence Zone. Geophys Res Lett 35:L16701. doi: 10.1029/2008GL034298

Menkes C, Lengaigne M, Marchesiello P, Jourdain NC, Vincent EM, Lefevre J, Chauvin F, Royer JF (2009) Comparison of cyclogenesis indices on seasonal to interannual time scales (in preparation)

Nicholls N (1985) Predictability of interannual variations of Australian seasonal tropical cyclone activity. Mon Weather Rev 113:1144-1149

Ramsay HA, Leslie LM, Lamb PJ, Richman MB, Leplastrier M (2008) Interannual variability of tropical cyclones in the Australian region: role of large-scale environment. J Clim 21:1083-1103. doi:10.1175/2007JCLI1970.1

Revell CG, Goulter SW (1986) South Pacific tropical cyclones and the southern oscillation. Mon Weather Rev 114:1138-1145

Reyment RA, Jörekog KG (1993) Applied factor analysis in the earth sciences, 2nd edn. Cambridge University Press, London, p 371

Royer JF, Chauvin F (2009) Response of tropical cyclogenesis to global warming in an IPCC AR-4 scenario assessed by a modified yearly genesis parameter. In: Elsner JB, Jagger TH (eds) Hurricanes and climate change. Springer, Berlin, pp 213234

Royer JF, Chauvin F, Timbal B, Araspin P, Grimal D (1998) A GCM study of the impact of greenhouse gas increase on the frequency of occurrence of tropical cyclones. Clim Change 38:307-343

Spencer H (2004) Role of the atmosphere in seasonal phase locking of El Niño. Geophys Res Lett 31:L24104. doi:10.1029/2004 GL021619

Takahashi K, Battisti DS (2007) Processes controlling the mean tropical Pacific precipitation pattern. Part II: the SPCZ and the southeast Pacific dry zone. J Clim 20:5696-5706. doi:10.1175/ 2007JCLI1656.1

Trenberth KE (1976) Spatial and temporal variations of the southern oscillation. Q J R Meteorol Soc 102:639-653

Trenberth KE, Smith L (2006) The vertical structure of temperature in the tropics: different flavors of El Niño. J Clim 19:4956-4970

Vecchi GA (2006) The termination of the 1997-98 El Niño. Part II: mechanisms of atmospheric change. J Clim 19:2647-2664

Vincent DG (1994) The south Pacific convergence zone (SPCZ): a review. Mon Weather Rev 122:1949-1970

Wang G, Hendon HH (2007) Sensitivity of Australian rainfall to inter-El Niño variations. J Clim 20:4211-4226

Ward JH (1963) Hierarchical grouping to optimize an objective function. J Am Stat Assoc 58(301):236-244

Xie P, Arkin PA (1997) Global precipitation: a 17-year monthly analysis based on gauge observations, satellite estimates, and numerical model outputs. Bull Am Meteorol Soc 78:2539-2558

Yin X, Gruber A, Arkin PA (2004) Comparison of the GPCP and CMAP merged gauge-satellite monthly precipitation products for the period 1979-2001. J Hydrometeorol 5:1207-1222 